\title{
Effect of Metamaterial Cells Array on a Microstrip Patch Antenna Design
}

\author{
Adelson M. Lima ${ }^{1,2}$ (D), Nilson Henrique O. Cunha ${ }^{1}$ (D) José P. da Silva ${ }^{1}$ (D) \\ ${ }^{1}$ Electrical Engineering Department, Federal University of Rio Grande do Norte/UFRN, Natal, Brazil. \\ adelsonmlima@gmail.com, nilson.ee@gmail.com,patroc@ct.ufrn.br \\ ${ }^{2}$ Technology and Engineering Department, Federal Rural University of the Semi-Arid Region/UFERSA, \\ Pau dos Ferros, Brazil
}

\begin{abstract}
In this paper, a microstrip patch antenna (MPA) design was developed to verify the performance of a metamaterial cell array (MTM) Capacitive Loaded Loop (CLL) immersed in the substrate. The metamaterial was obtained from metal laminates designed inside a dielectric material, with dimensions carefully calculated to have the effective negative permittivity and permeability, consequently the negative refractive index, in a certain frequency range. In this case, the geometric control of the unit cell parameters allowed its organization in a periodic arrangement to be immersed in the MPA substrate. Simulated and experimental results were obtained and compared for some parameters of the antenna, which showed a good relationship between MTM and MPA performance.
\end{abstract}

Index Terms - Antenna design, cell array, metamaterial, substrate.

\section{INTRODUCTION}

The continuous search for new technologies has led researchers to study more and more the application of metamaterials (MTMs) in wireless communication system [1]. As it covers a wide range of materials, its properties can be exploited to control and improve the propagation characteristics, thus affecting the antennas functioning, in particular the microstrip patch antenna (MPA) [1]. MTMs are structures artificially obtained, usually periodic and can present electrical permittivity $(\varepsilon)$, magnetic permeability $(\mu)$ and refractive index ( $n)$ simultaneously negative [2]-[4].

In literature, several geometries are characterized as MTMs structures that are applied in the patch, within the substrate and in the ground plane of MPAs, aiming to optimize their performance and its parameters [1], [3]-[15]. For projects with metamaterials in the patch, it was proposed in [1], to use a Capacitive Loaded Split Rectangular Loop (CLL) resonator to reduce and control the propagation of electromagnetic waves. In the project by [6], a wireless local area network (WLAN) antenna used resonators with MTM based on epsilon negative (ENG) transmission line (TL) with probe-fed. It obtained a greater bandwidth (BW) 2.3 times greater than the standard antenna and greater width of the axial ratio. In a ultra wideband (UWB) antenna [7], a circular SRR resonator was used with the closing of the inner ring. Optimized BW by $146.56 \%$ and gain of $8.57 \mathrm{dBi}$. For a miniaturized antenna to operate in five bands [12], the ring-shaped patch used an MTM resonator type Rectangular Complementary Split Ring Resonator (RCSRR) inside the ring. Thus, it reduced the dimensions by $46.8 \%$ and increased the BW. In a WLAN antenna [16], the authors proposed to use SRR in square rings and PIN diodes 
Journal of Microwaves, Optoelectronics and Electromagnetic Applications, Vol. 19, No. 3, September 2020 DOI: http://dx.doi.org/10.1590/2179-10742020v19i3886

integrated with MTM cells, to control the beam direction. MTMs were inserted next to the antenna patch. This achieved a maximum gain of $7 \mathrm{~dB}$ to $4.9 \mathrm{GHz}$ and increased BW by $40 \%$. According to [17], an antenna with an MTM type Complementary Split Ring Resonators (CSRRs) in hexagonal form has been proposed. It achieved a 5.7\% reduction in operating frequency, reflection coefficient $\left(\mathrm{S}_{11}\right)$ from $-34 \mathrm{~dB}$ at $2 \mathrm{GHz}$, greater gain and the radiation is unchanged. In [18], it was proposed a superstrate antenna using SRR type MTM cells in square rings. It achieved a gain of $9.991 \mathrm{~dB}$ at $4.521 \mathrm{THz}$ and $1.11 \mathrm{~dB}$ at $3.846 \mathrm{THz}$, a decrease in half-power beam width (HPBW) compared to the conventional antenna. For [19], the antenna used Split Ring Resonator cells and thin wires (SRR/TW) over the antenna patch. At $303 \mathrm{GHz}$, it improved the beam focus, gain, $\mathrm{BW}$ and $\mathrm{S}_{11}(1.1 \mathrm{~dB}, 14.73 \mathrm{GHz}$ and $12.63 \mathrm{~dB}$, respectively), in addition to directivity and radiation. At $10 \mathrm{GHz}$ it improved by $1.5 \mathrm{~dB}, 10.15$ $\mathrm{MHz}$ and $2 \mathrm{~dB}$ for gain, $\mathrm{BW}$ and $\mathrm{S}_{11}$, respectively.

In projects with metamaterials within the substrate, MTMs SRR cells with square geometry helped to obtain frequency ranges $(5.47-5.6 \mathrm{GHz}$ and 5.72 - 5.82 GHz) for WLAN and increased gain [9]. In [13], the SRR labyrinth geometry obtained an increase in BW by $600 \%$, better voltage standing wave ratio (VSWR) by $1.5 \%$ and a miniaturized antenna by $400 \%$. And an antenna for $\mathrm{THz}$ [20], obtained a high gain using a rectangular MTR type SRR.

On the ground plane, an antenna for the frequencies global system for mobile communications (GSM), worldwide interoperability for microwave access (WiMAX), Bluetooth and WLAN [11], obtained a reduction in electromagnetic absorption with MTM SRR in hexagonal rings, by $66.47 \%$ and $66.52 \%$ for $1.8 \mathrm{GHz}$ and $2.4 \mathrm{GHz}$. In a THz antenna [15], a circular shaped Split Ring Resonator (SRR) is used to construct the MTM surface. It obtained reduced antenna, $S_{11}$ of $-65 \mathrm{~dB}$ and the gain changed significantly in $1.02 \mathrm{THz}$.

Another form of design is to insert cells on both sides of a dielectric plate, or in the patch and ground plane. In a microstrip dipole antenna [4], cells with divided circular geometry, such as Split Ring Resonator (SRR), obtained an increase in BW, gain and decrease in the value of the $\mathrm{S}_{11}$. For a high gain antenna in $\mathrm{THz}$ [21], it was used a unit cell of the axially symmetric fishnet with a low index MTM (LIM). Optimized the gain by $4 \mathrm{~dB}$, directivity and better radiation efficiency. In a UWB antenna [22], the authors used a Symmetric Split Ring Resonator (SSRR) MTM cell in divided circular rings. It was obtained a BW of $128.3 \%$ and a gain of $6.12 \mathrm{dBi}$. Finally, a combination of square resonant rings (SRR) and complementary split ring resonator (CSRR) [23], was performed on a $2.4 \mathrm{GHz}$ antenna. The SRR was inserted next to the feed line, while the CSRR was below the feed line, in ground plane. Achieved $4.55 \%$ BW without affecting coupling and directivity.

In adittion, another characteristic of projects is the use of the transmission line as an MTM resonator [8], in which a miniaturized antenna is based on the active MTM resonator used in transmission line. With this, it was obtained a greater gain than the traditional antenna.

On the other hand, a multiple input multiple output (MIMO) antenna inserted the CLL type MTM 
Journal of Microwaves, Optoelectronics and Electromagnetic Applications, Vol. 19, No. 3, September 2020 DOI: http://dx.doi.org/10.1590/2179-10742020v19i3886

cells [10], next to the feed line of each antenna to reduce electromagnetic interference and increase the isolation between the two antennas. As a result, good isolation with less than $25 \mathrm{~dB}$ and a wide bandwidth of $65.5 \%$ was achieved.

Some studies also report other types of resonator designs, such as MTM designs reconfigurable for multiple frequencies in $\mathrm{THz}$ with Electric Split Ring Resonator (eSRR) cells [24], based on microelectromechanical systems in the resonators. In [25], a sensor was proposed that uses a microwave technique with coupled antenna. It used a rectangular split ring resonator (SRR) MTM cell. It obtained a high Q factor, reduced size, good sensitivity and high repeatability for detection applications. Finally, a resonator based on an RLC circuit modified to $8.84 \mathrm{GHz}$ [26], was based on a conventional rectangular SRR, obtaining a greater BW at $3.4 \mathrm{GHz}$.

Based on these studies, the present work has as its main contribution the analysis of a MPA composed by a MTM substrate obtained from an arrangement of unit cells like Capacitive Loaded Loop (CLL) immersed in the substrate, designed to resonate at $5.8 \mathrm{GHz}$, when placed between copper laminates constituting the ground plane and the radiant antenna element. Thus, the proposal is to investigate the influence of MTM cell arrangement on the parameters of the microstrip antenna. For this, three MTM arrays were built, one for each MPA, with variations in the distances $\left(\Lambda_{0}\right)$ between the cells. The results obtained numerically by simulation were compared with measured results, obtained from the construction of the prototypes of the proposed structural models. The simulations were performed using ANSYS HFSS ${ }^{\circledR}$ software version 19.2, and the necessary formulations for the cells, MPA and graphics designs were simulated using open source software for numerical computation Scilab. The computer specifications are $8 \mathrm{~GB}$ RAM, with Core i5 and $1.8 \mathrm{GHz}$ processor.

This paper is structured as follows: Section 2 presents the metamaterial design. Section 3 describes the design of the MPA with and without MTM. Section 4 presents the discussions and results. Finally, the conclusions are presented in Section 5.

\section{Metamaterial Design}

To obtain MTMs used in MPAs project proposed in this work, initially the unit cell presented in [1], [3], [5] was structurally modified to operate in the project's frequency range of interest (5.8 GHz). Next, an array of unit cells was organized to obtain the metamaterial substrate used in the MPAs. The characterization of the effective permittivity $\left(\varepsilon_{e f f}\right)$ and the effective permeability $\left(\mu_{e f f}\right)$ of the unit cell that originated the arrangement was made by adjusting the copper laminate dimensions that constitutes it, so that electromagnetic interactions occur that make them negative in MPA operating frequency. Important to highlight that for a unit cell to perform well as a metamaterial, its geometry must be much smaller than the operating wavelength. This characteristic is essential to obtain the negative $\varepsilon, \mu$ and $n$ parameters [12], [16], [27], [28].

In some cases, cell dimensions do not meet the desired results, so it becomes necessary to gradually adjust their dimension so that the computational results meet the conditions to become metamaterial. 
Journal of Microwaves, Optoelectronics and Electromagnetic Applications, Vol. 19, No. 3, September 2020 DOI: http://dx.doi.org/10.1590/2179-10742020v19i3886

The excitation of a unit cell, for the case of simulation analysis, requires the oblique incidence of a plane electromagnetic wave, in addition to the application of suitable periodic boundary conditions, to obtain the scattering matrix $(S)$ parameters correctly, i.e. the reflection coefficient $\left(S_{11}\right)$ and the transmission coefficient $\left(S_{12}\right)$ [27], [29]. These parameters are calculated according to (1) and (2) [16], [28], [29]. In this context, once the parameters $S_{11}$ and $S_{12}$ are obtained by simulation using ANSYS HFSS $^{\circledR}$ software, they are exported and mathematically manipulated through an algorithm developed in Scilab software to obtain $\varepsilon_{\text {eff, }} \mu_{\text {eff }}$ and $n$ [16], [28], [29]. Numerical simulations used a tool with a mathematical model based on the finite element method.

$$
\begin{gathered}
\varepsilon_{e f f}=\left(\frac{2}{j k_{0} l_{1}}\right)\left(\frac{1-S_{11}-S_{12}}{1+S_{11}+S_{12}}\right) \\
\mu_{e f f}=\left(\frac{2}{j k_{0} l_{1}}\right)\left(\frac{1+S_{11}-S_{12}}{1-S_{11}+S_{12}}\right) \\
n=\sqrt{\varepsilon_{e f f .} \mu_{e f f}}
\end{gathered}
$$

Where $l_{l}$ is the maximum length of the unit cell, and $k_{0}$ is the wave number in free space.

Fig. 1a shows the cell and parameters with dimensions ( $a=2.6 \mathrm{~mm}, b=4.4 \mathrm{~mm}, c=2 \mathrm{~mm}, d=1.65$ $\mathrm{mm}, e=0.5 \mathrm{~mm}, f=1.2 \mathrm{~mm}, g=3.8 \mathrm{~mm}, h=0.2 \mathrm{~mm}, i=1.55 \mathrm{~mm}$ ) on a fiberglass substrate (FR4) with relative permittivity $\varepsilon_{r}=4.4$, loss tangent $\operatorname{tg} \delta=0.02$ and using $0.03 \mathrm{~mm}$ thick cooper laminate. Fig. $1 \mathrm{~b}$ shows the real part $\varepsilon_{\text {eff, }} \mu_{\text {eff }}$ and $n$ of the cell. The simulation for the unit cell (Fig. 1a) used the ANSYS HFSS $^{\circledR}$ software, as well Scilab for the characterization of the parameters and graphs of $\varepsilon_{e f f}$, $\mu_{\text {eff }}$ and $n$ (Fig. 1b).
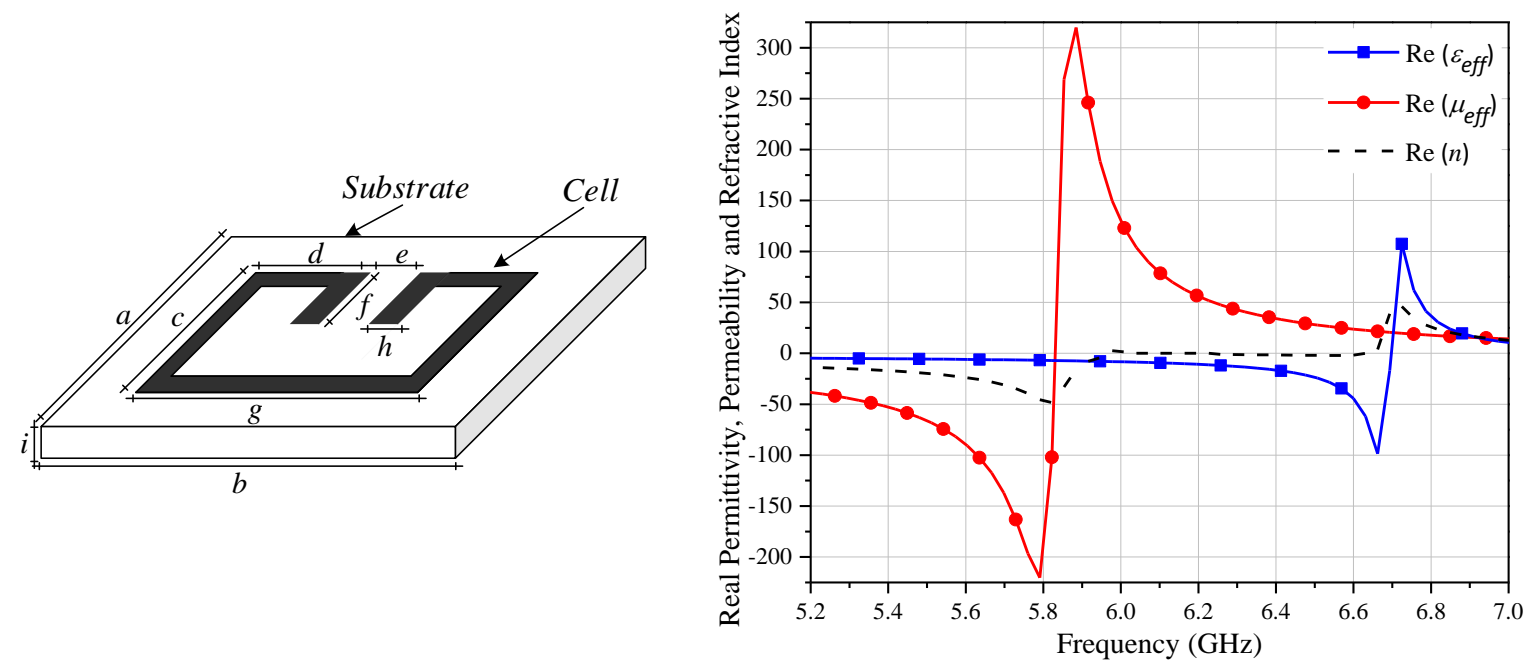

Fig. 1. (a) Schematic of MTM cell, (b) Parameters $\varepsilon_{e f f}, \mu_{e f f}$ and $n$.

\section{ANTENNAS DESIGNS AND CONFIGURATIONS}

In this study, MPAs were developed for $5.8 \mathrm{GHz}$ applications. The antenna dimensions were obtained from the equations found in the literature for rectangular geometries, as follows the length $(L p)$ and 
width $(W p)$ of the antenna patch [30], [31]:

$$
\begin{gathered}
W p=\frac{c}{2 f_{0} \sqrt{\left(\varepsilon_{r}+1\right) / 2}} \\
L_{e f f}=\frac{c}{2 f_{0} \sqrt{\varepsilon_{r e f f}}} \\
\Delta L=\frac{0.412 h\left(\varepsilon_{r e f f}+0.3\right)(w / h+0.3)}{\left(\varepsilon_{r e f f}-0.258\right)(w / h+0.8)} \\
L p=L_{r e f f}-2 \Delta L
\end{gathered}
$$

From $L p$ and $W p$, the results obtained for the length $(L g)$ and width $(W g)$ of the ground plane, can be approximated by the following equations [30]:

$$
\begin{gathered}
L g=6 h+L p \\
W g=8 h+W p
\end{gathered}
$$

The MPAs were excited from a quarter wavelength feed line integrated into the patch to have a maximum impedance matching between the $50 \Omega$ line and the radiant element [31], [32]. Simulated and constructed prototypes were made on fiberglass substrates (FR4) with $\varepsilon_{r}=4.4, \operatorname{tg} \delta=0.02$. The MPAs dimensions and their schemes are presented in Fig. 2. The final values of the dimensions, obtained for the antenna, are shown in Table 1. The MPA simulation used the ANSYS HFSS ${ }^{\circledR}$ software.

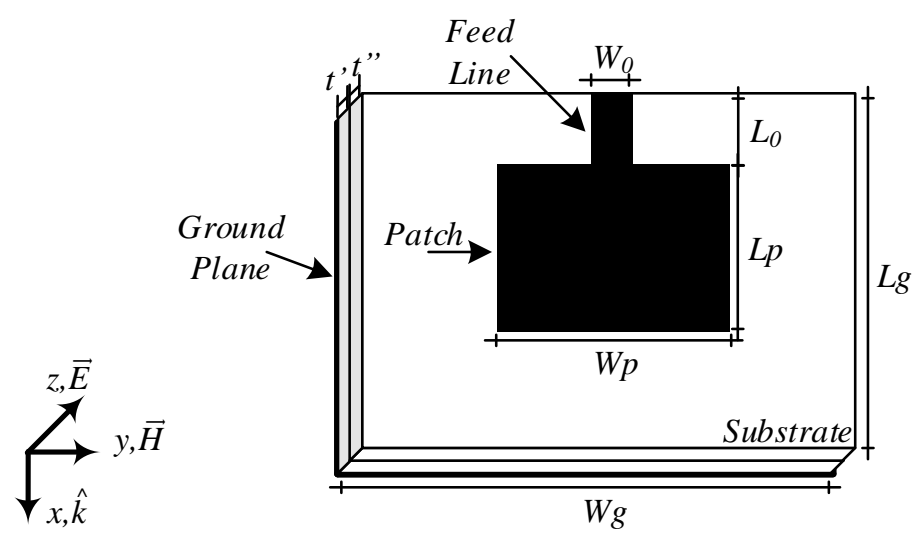

Fig. 2. Microstrip patch antenna.

TABLE I. MPA PARAMETER DIMENSIONS

\begin{tabular}{cccc}
\hline Parameters & Values $(\mathbf{m m})$ & Parameters & Values $(\mathbf{m m})$ \\
\hline Ground length $(L g)$ & 29.2 & Feed line $\left(L_{0}\right)$ & 6.5 \\
\hline Ground width $(W g)$ & 41.6 & Line width $\left(W_{0}\right)$ & 2.7 \\
\hline Patch length $(L p)$ & 10 & First slab thickness $\left(t^{\prime}\right)$ & 1.55 \\
\hline Patch width $(W p)$ & 16 & Second slab thickness $\left(t^{\prime \prime}\right)$ & 1.55 \\
\hline
\end{tabular}


In addition, for the MPAs construction, two FR4 slabs with dimensions of $L g \times W g$ and thicknesses ( $t^{\prime}$ and $\left.t^{\prime \prime}\right)$ were used. For MPAs with MTM, on the first slab with thickness $\left(t^{\prime}\right)$, the metamaterial cell array was designed on one side, while on the other side the copper laminate was maintained. On the second slab with thickness ( $t$ "), on one side the antenna patch was designed, and on the other side the copper laminate was removed. Then the two slabs were overlapped, such that the unit cell array was positioned between the two slabs, equidistant from the ground plane and the antenna patch, as seen in Fig. 3 and Fig. 4. Thus, the FR4 slabs used formed a substrate with a total thickness of $3.1 \mathrm{~mm}$ using $0.03 \mathrm{~mm}$ thick copper laminate on its sides.

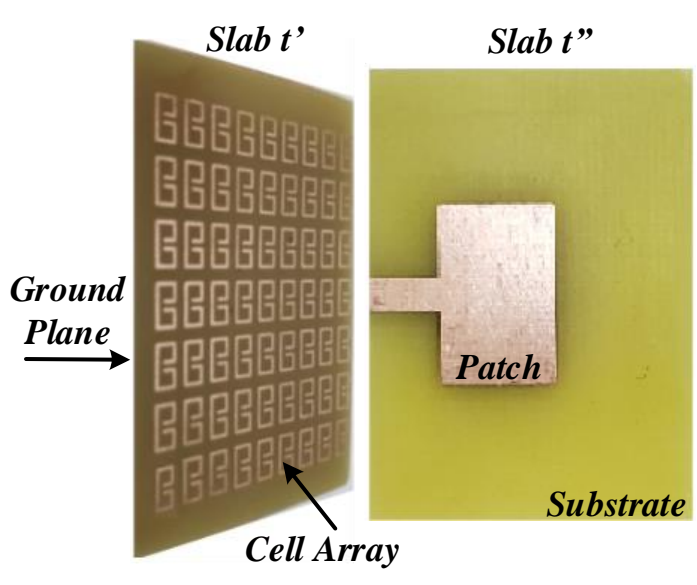

(a)

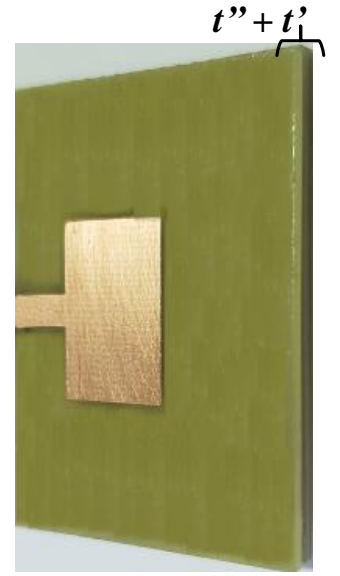

(b)

Fig. 3. Assembly of slabs (a) Slab t' and $t^{\prime \prime}$, (b) Slabs overlapped.

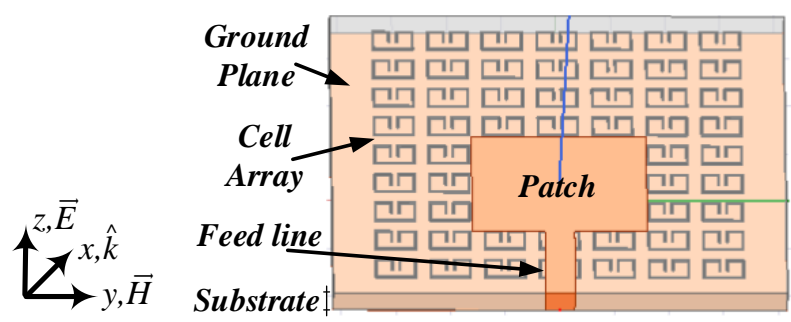

(a)

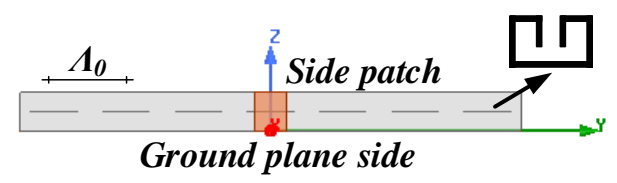

(b)

Fig. 4. Cells within MPA substrate (a) Top view, (b) Front view.

Fig. 5 shows the prototypes of the proposed MTM based in $9 \times 7$ arrays of unity cells immersed in the substrate for each antenna. The number of unitary cells was determined according to the size of the antenna substrate. Each unit cell type CLL was distributed and organized periodically in the direction $\pm \hat{x}$ and $\pm \hat{y}$, to behave like a microwave RLC resonant circuit, as shown in Fig. 6 . Where the CLL gap represents the capacitance $(\mathrm{C})$, while the metallic laminate represents the inductance $(\mathrm{L})$ and the resistance (R). In addition, the distance between the cells creates a capacitance, as well as a mutual inductance, which will determine the strength of the coupling. 
The arrangements were analyzed empirically considering the variation $\left(\Lambda_{0}\right)$ in the direction $\pm \hat{y}$ between the center of the cells of $4 \mathrm{~mm}, 5 \mathrm{~mm}$ and $6 \mathrm{~mm}$ to verify the effect of the coupling [33]-[35].

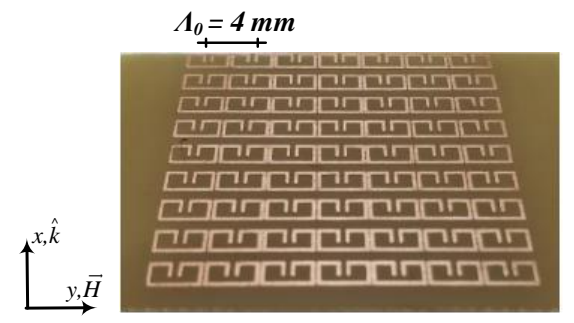

(a)

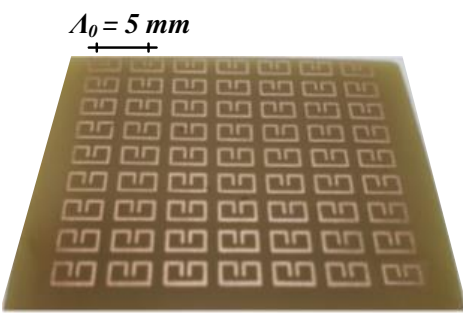

(b)

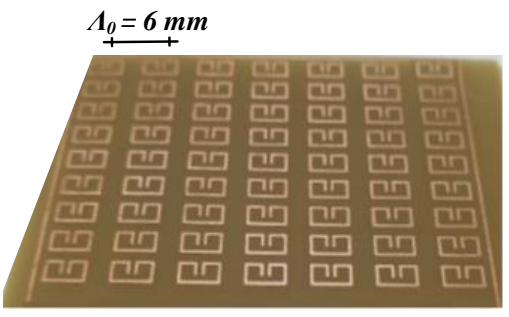

(c)

Fig. 5. Cells array MTM (a) $4 \mathrm{~mm}$, (b) $5 \mathrm{~mm}$, (c) $6 \mathrm{~mm}$.

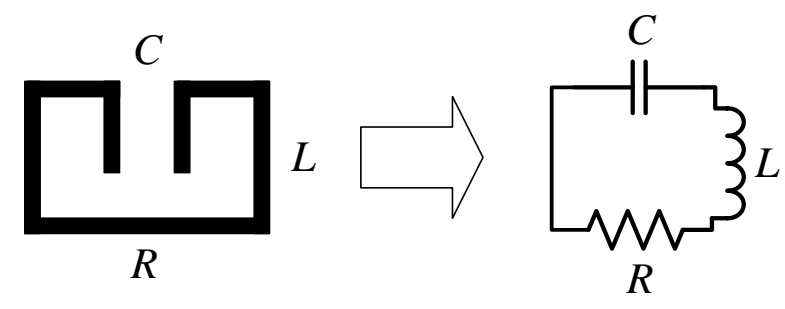

Fig. 6. Equivalent cell circuit model.

\section{RESULTS AND DISCUSSIONS}

To validate the results and verify the performance of MTM based MPAs, numerical simulations were performed using ANSYS HFSS version 19.2 software based on finite element method and prototypes were manufactured for experimental measurements performed by a vector network analyzed (Keysight E5071C) with measurement range from $9 \mathrm{kHz}$ to $4.5 \mathrm{GHz}$. The graphics were simulated using open source Scilab software.

Fig. 7 shows the simulated and measured results for the reflection coefficient parameter $\left(\mathrm{S}_{11}\right)$ for MPA without MTM and MPAs with substrates based on MTMs, considering the distance $\left(\Lambda_{0}\right)$ between the cell centers along the direction $\pm \hat{y}\left(\Lambda_{0}\right)$ and dimension $W g$ for $4 \mathrm{~mm}, 5 \mathrm{~mm}$ and $6 \mathrm{~mm}$. It is observed that small variations in $\Lambda_{0}$ can cause significant changes in $\mathrm{BW}$ and impedance matching between the feed line and the patch. Therefore, in the variation of $\Lambda_{0}=6 \mathrm{~mm}$ (Fig. 7d) it presented the lowest reflection coefficient $\left(S_{11}\right)$, while the largest bandwidth was obtained by $\Lambda_{0}=5 \mathrm{~mm}$ (Fig. $7 \mathrm{c}$ ).

In addition, with the graphs of parameter $S_{11}$ showing values within the range of $-10 \mathrm{~dB}$, it is clear that increasing $\Lambda_{0}$ between cells results in decreased resonance frequency while increasing bandwidth. It is also evident that in the desired region of antenna operation (Fig. 1b), the CLL cell has a magnetic characteristic, different from the electrical one. These characteristics induce the $\varepsilon_{\text {eff }}$ of the antenna substrate to increase, which causes the resonance frequencies to decrease, allowing a miniaturization of the antennas, since lower frequencies can be achieved with the smaller dimensions for the antennas [31]. 
Journal of Microwaves, Optoelectronics and Electromagnetic Applications, Vol. 19, No. 3, September 2020 DOI: http://dx.doi.org/10.1590/2179-10742020v19i3886

With the measurements, it is clear that there is a good agreement between the simulated and the measured results. It can be seen from Fig. $7 \mathrm{~b}$ that the increase in BW occurred due to the emergence of an artificial mode $\left(f_{l}\right)$ generated by the presence of the unit cell array introduced into the substrate.

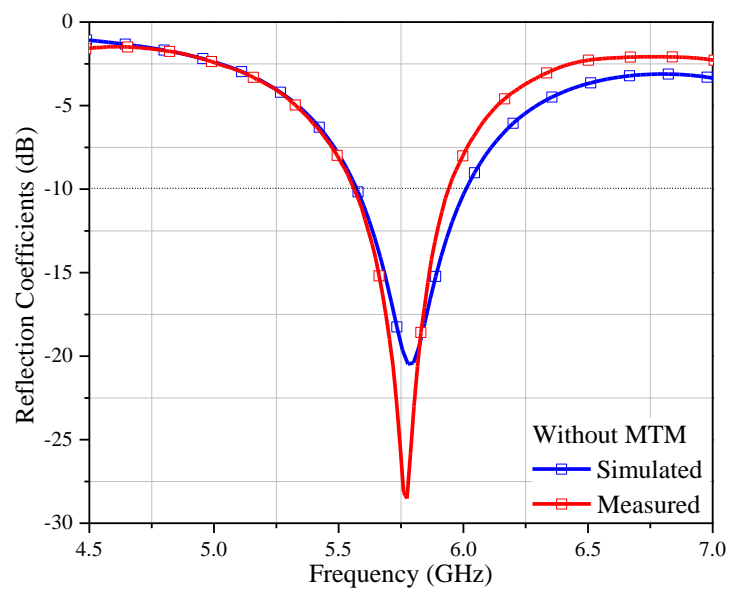

(a)

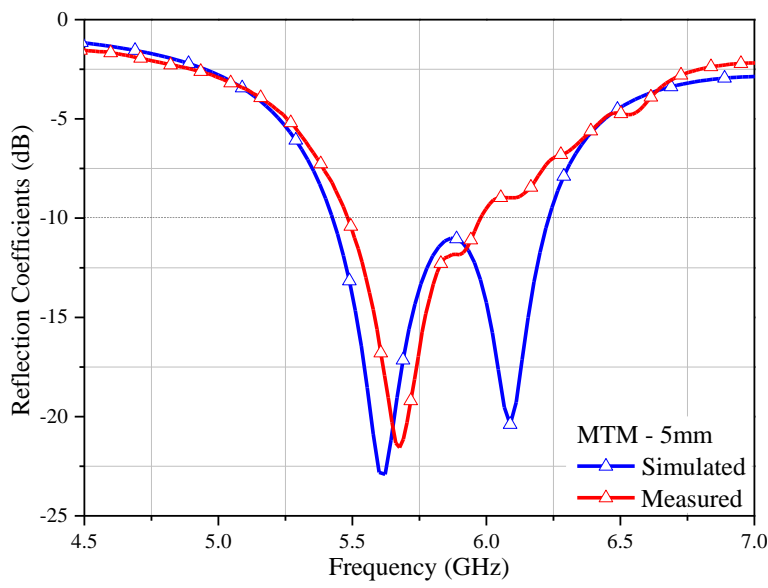

(c)

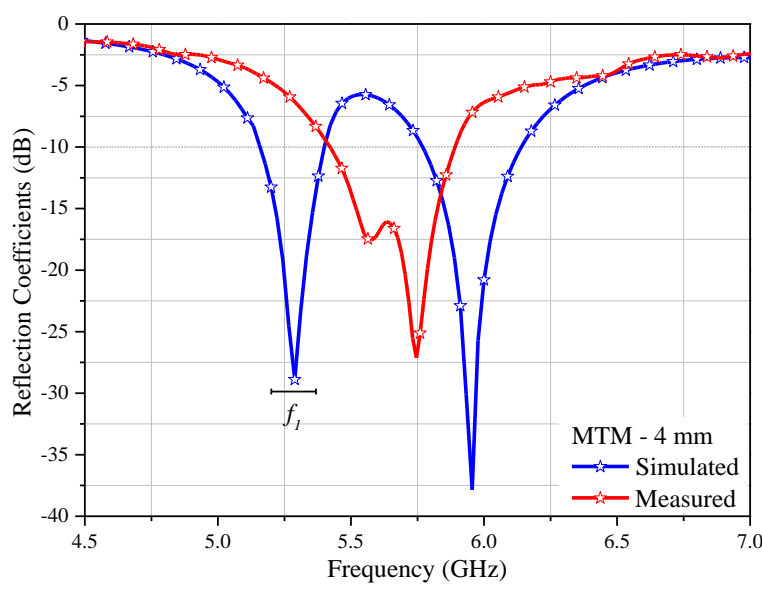

(b)

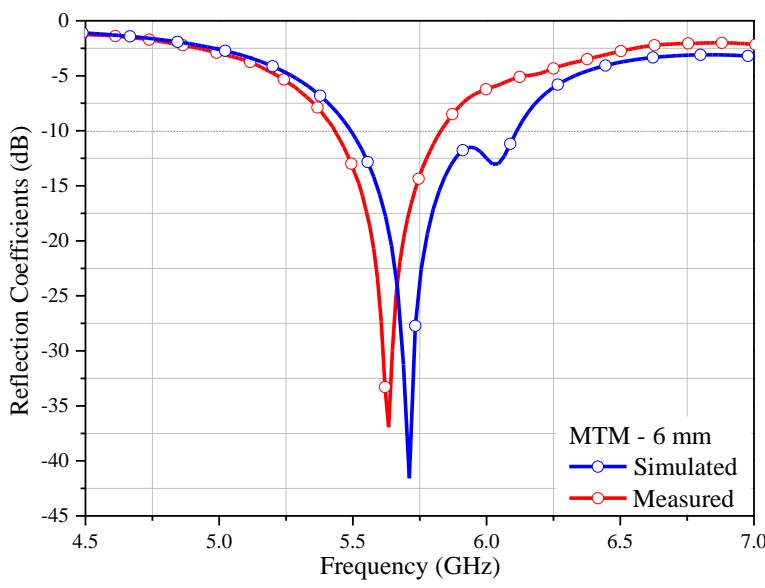

(d)

Fig. 7. Comparison of simulated and measured MPAs results for $\mathrm{S}_{11}$ (a) Without MTM (b) $\Lambda_{0}=4 \mathrm{~mm}$, (c) $\Lambda_{0}=5 \mathrm{~mm}$,

(d) $\Lambda_{0}=6 \mathrm{~mm}$.

Fig. 8 and Fig. 9 show the electrical field distribution in the MPA without MTM patch and ground plane (Fig. 8) and the MPA with MTM (Fig. 10), where it is found that insertion of the MTM cells into the substrate causes an expansion in electrical widening of the physical structure of the patch. According to the electric field distribution in the ground plane of Fig. 9, the appearance of electric fields along the $\pm \hat{y}$ direction is observed, giving rise to the emergence of artificial modes (AM). As the physical dimensions are inversely proportional to the frequency [31], one can identify the artificial and natural modes in the $S_{11}$ curves. Therefore, it is evident that the artificial resonant mode predicted in simulations was validated in the measurements through $\mathrm{S}_{11}$ parameter. 


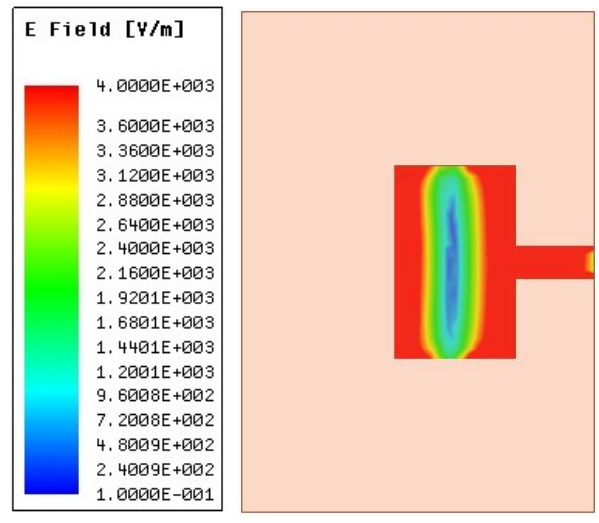

(a)

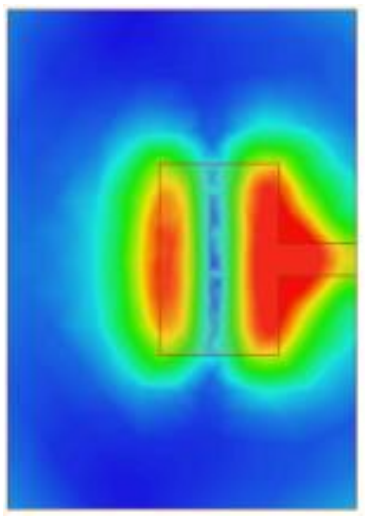

(b)

Fig. 8. Distributions of the electric field on the MPA without MTM (a) Patch, (b) Ground plane.

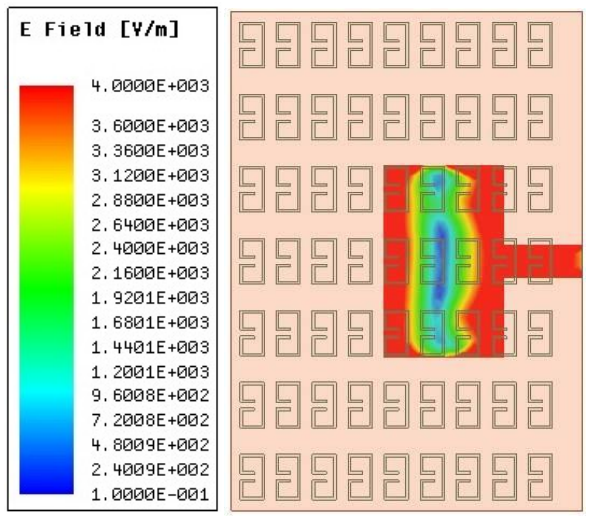

(a)

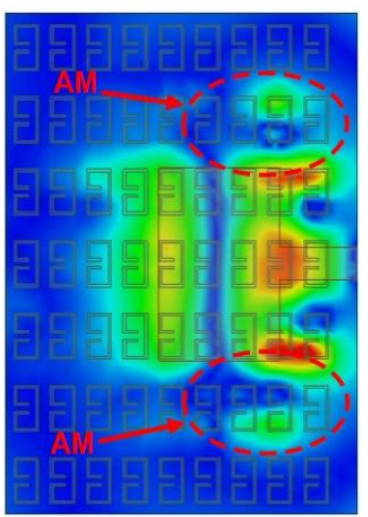

(b)

Fig. 9. Distributions of the electric field on the MPA with MTM $\left(\Lambda_{0}=6 \mathrm{~mm}\right)$ (a) Patch, (b) Ground plane.

Fig. 10 shows the impedance values using the Smith Chart considering a normalization impedance of $50 \Omega$. Based on simulations, it is observed an additional loop for the MPA curve with MTM compared to MPA without MTM, this response is clearly compatible with results measured in Fig. 10b and Fig. 10c. The reason for this unexpected loop is the appearance of an artificial mode, at frequencies close to the resonant frequency, caused by the use of the metamaterial substrate, leading to an increase in bandwidth and influencing the impedance matching. Regarding impedance matching, it is observed that for all cases of MPA with MTM there was a better impedance matching in relation to the antenna without MTM. For MPA with MTM of $\Lambda_{0}=6 \mathrm{~mm}(50.6+\mathrm{j} 0.6 \Omega)$ showed a better result than MPA without MTM $(41.5+\mathrm{j} 1 \Omega)$. 


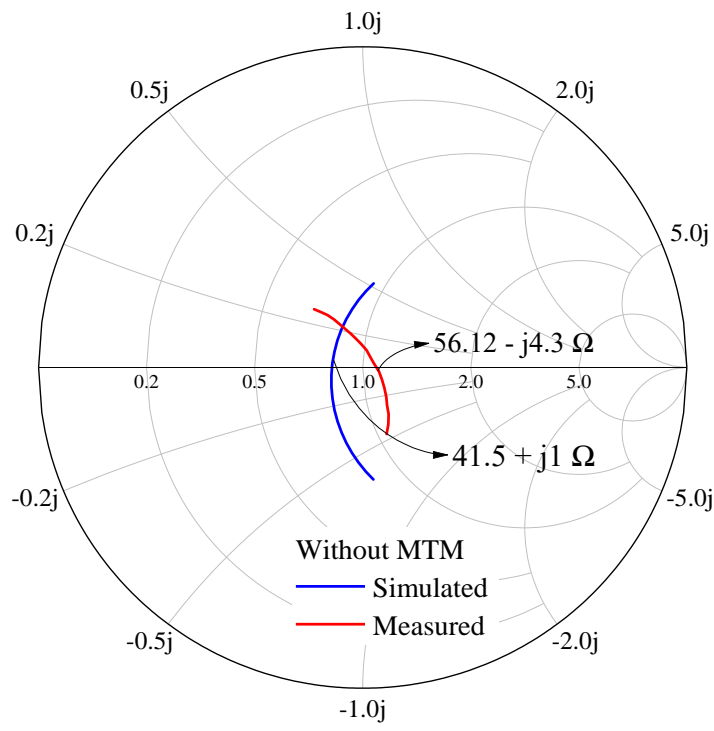

(a)

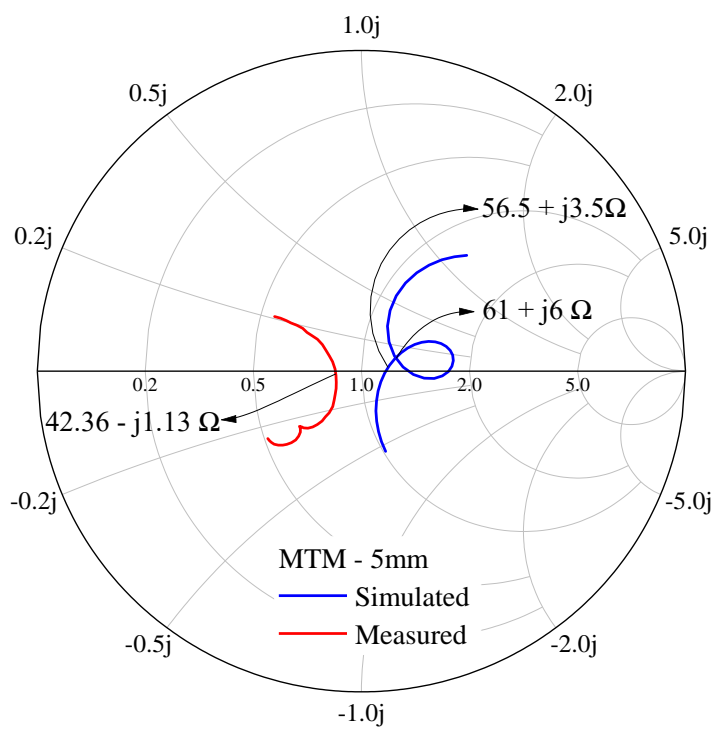

(c)

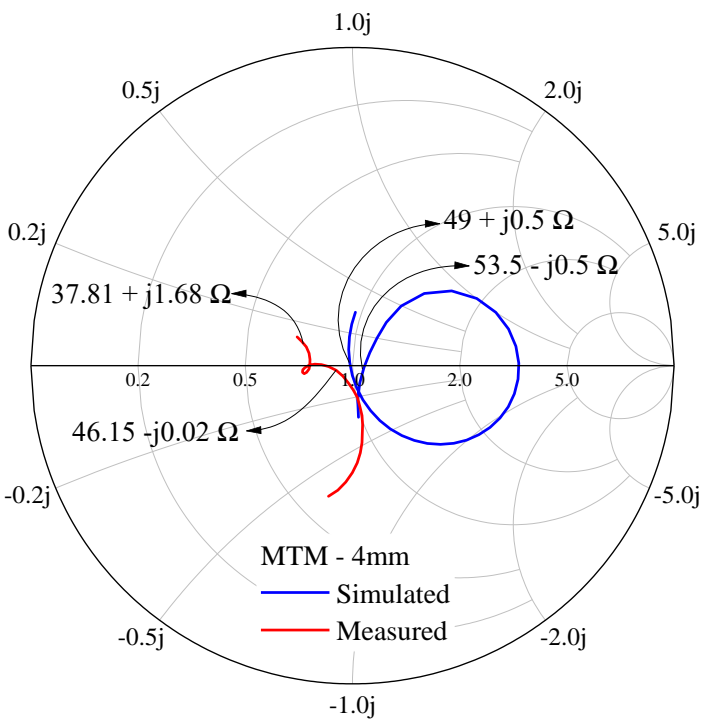

(b)

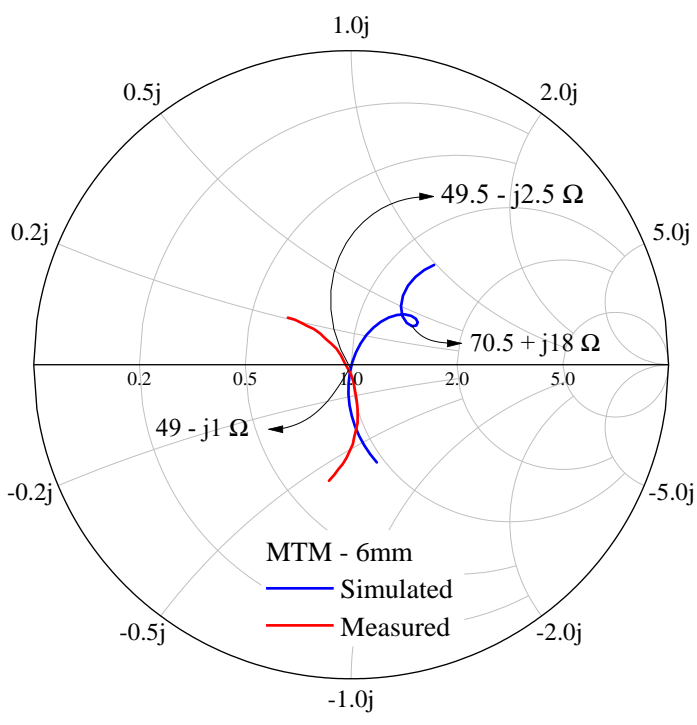

(d)

Fig. 10. Comparison of the simulated Smith chart diagram and MPAs measurement (a) Without MTM, (b) $\Lambda_{0}=4 \mathrm{~mm}$, (c) $\Lambda_{0}=5 \mathrm{~mm}$, (d) $\Lambda_{0}=6 \mathrm{~mm}$.

Fig. 11 shows the simulated results for the voltage standing wave ratio (VSWR), with a desirable value equal to or less than 2 [36], for MPAs design. When modifying the distance between the cells, the MPA with $\Lambda_{0}$ of $6 \mathrm{~mm}$ obtains the lowest VSWR value, as well as obtaining a better impedance matching, which caused a lower reflection coefficient, as shown in Fig. 7d.

Fig. 12 shows the simulation of the radiation diagram for MPAs. Based on the real part of the total electric field, it appears that MPAs with MTM have additional losses, this is due to the insertion of metal laminates in its structure. It is noticed that the antennas with MTM have practically the same level of electric field, since the amount of metallic laminate of the cells in the antennas was the same. Another 
Journal of Microwaves, Optoelectronics and Electromagnetic Applications, Vol. 19, No. 3, September 2020 DOI: http://dx.doi.org/10.1590/2179-10742020v19i3886

important aspect of analysis is the influence of MTM on the rear lobe of MPAs, that is, it is possible to analyze that the antennas with $\Lambda_{0}=5 \mathrm{~mm}$ had a decrease in their module, on the other hand the antennas with $\Lambda_{0}=4 \mathrm{~mm}$ and $\Lambda_{0}=6 \mathrm{~mm}$ presented the rear lobe radiation diagram similar to that of the standard antenna. These effects are due to the scattering created by the MTM cells strongly influenced by the distance between the cells and it is noticed that depending on the configuration, distance between the cells and periodic disposition, the rear lobe may decrease or increase.

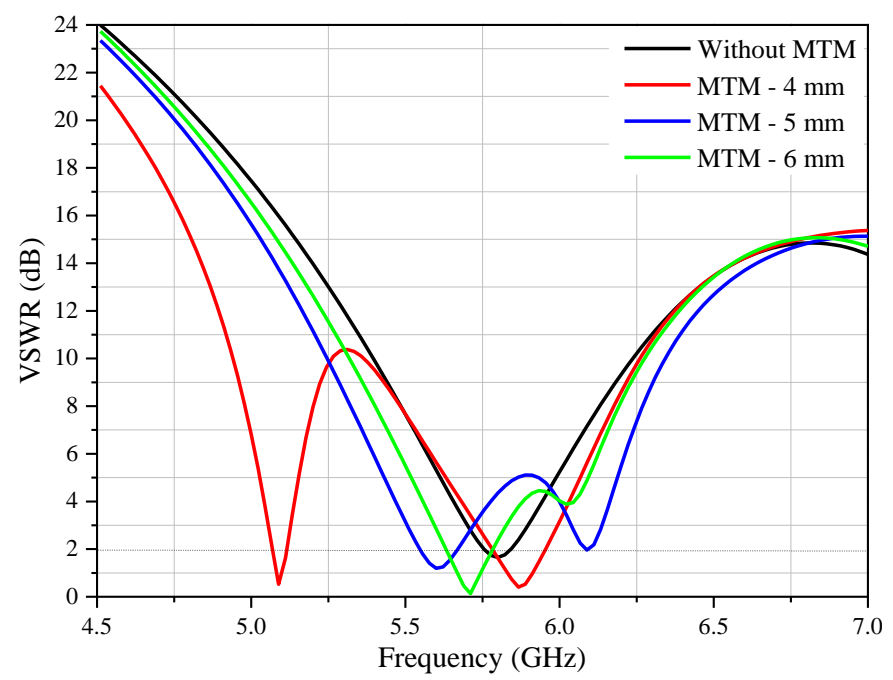

Fig. 11. Comparison of the simulated VSWR of MPAs (a) Without MTM (b) $\Lambda_{0}=4 \mathrm{~mm}$, (c) $\Lambda_{0}=5 \mathrm{~mm}$ (d) $\Lambda_{0}=6 \mathrm{~mm}$.

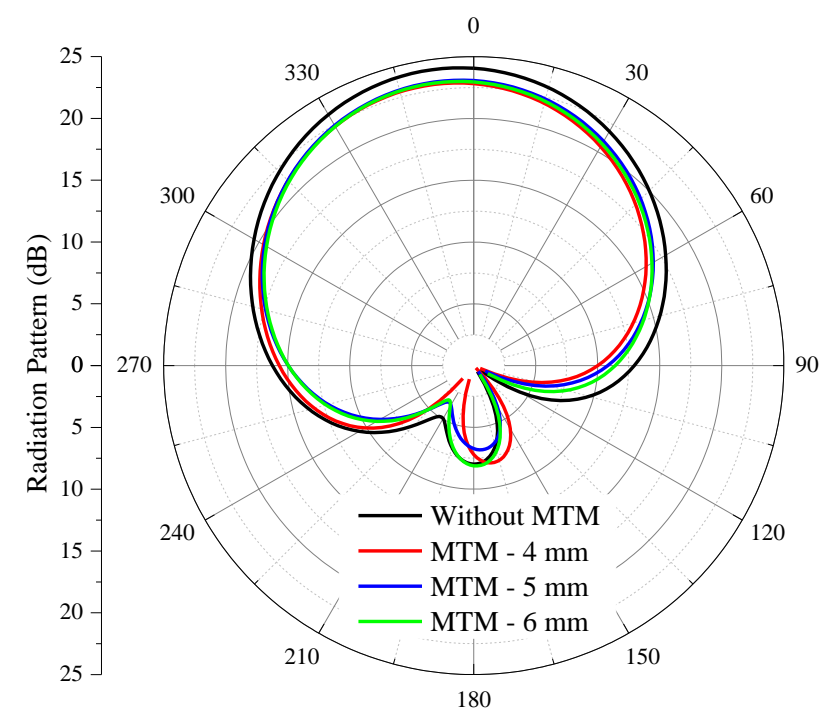

Fig. 12. Simulated radiation pattern of MPAs (a) Without MTM (b) $\Lambda_{0}=4 \mathrm{~mm}$, (c) $\Lambda_{0}=5 \mathrm{~mm}$ (d) $\Lambda_{0}=6 \mathrm{~mm}$.

Fig. 13 shows the E plan and $\mathrm{H}$ plan of the MPA radiation diagram without MTM and with MTMs. It is observed that the MPA with MTM of $\Lambda_{0}=5 \mathrm{~mm}$ (Fig. 13c), has a greater gain in relation to the others that have MTM, while that with $\Lambda_{0}$ of $4 \mathrm{~mm}$ (Fig. 13b) has the lowest gain. In addition, the greatest gain is achieved when theta equal to $-15^{\circ}$ for MPA without MTM, and as the grating of the metamaterial cells increases, the direction of maximum propagation rotates to theta equal to $-40^{\circ}$ in the case with of $6 \mathrm{~mm}$ between cells (Fig. 13d). 
Journal of Microwaves, Optoelectronics and Electromagnetic Applications, Vol. 19, No. 3, September 2020 DOI: http://dx.doi.org/10.1590/2179-10742020v19i3886

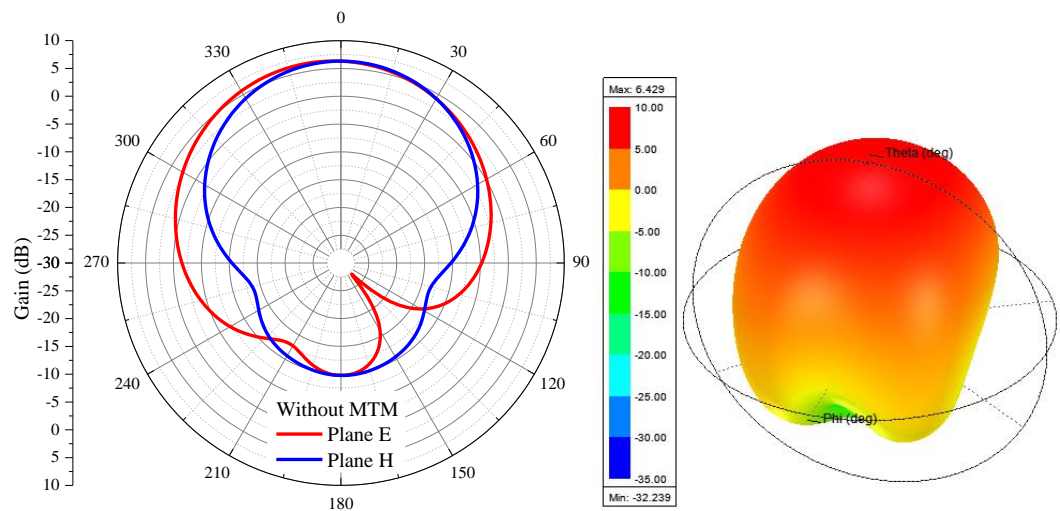

(a)

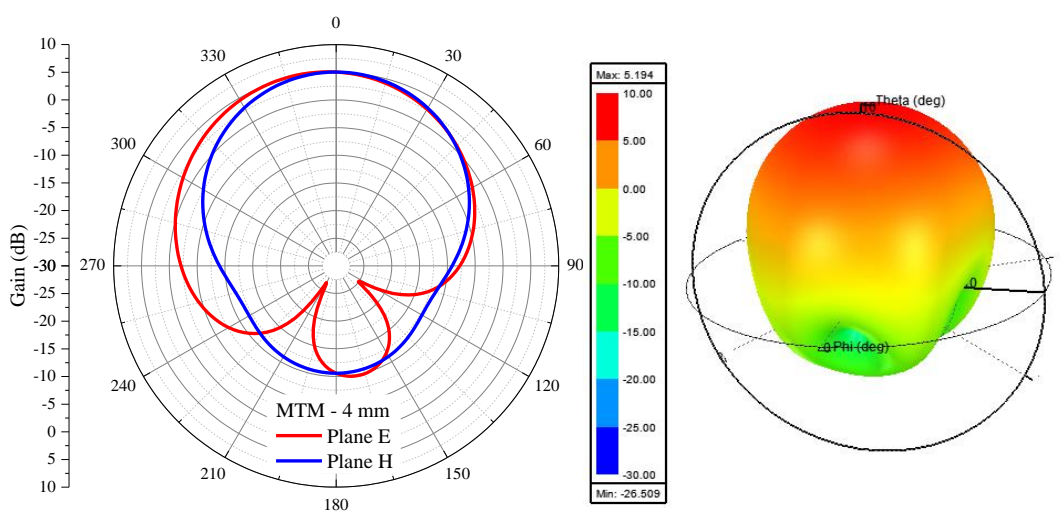

(b)

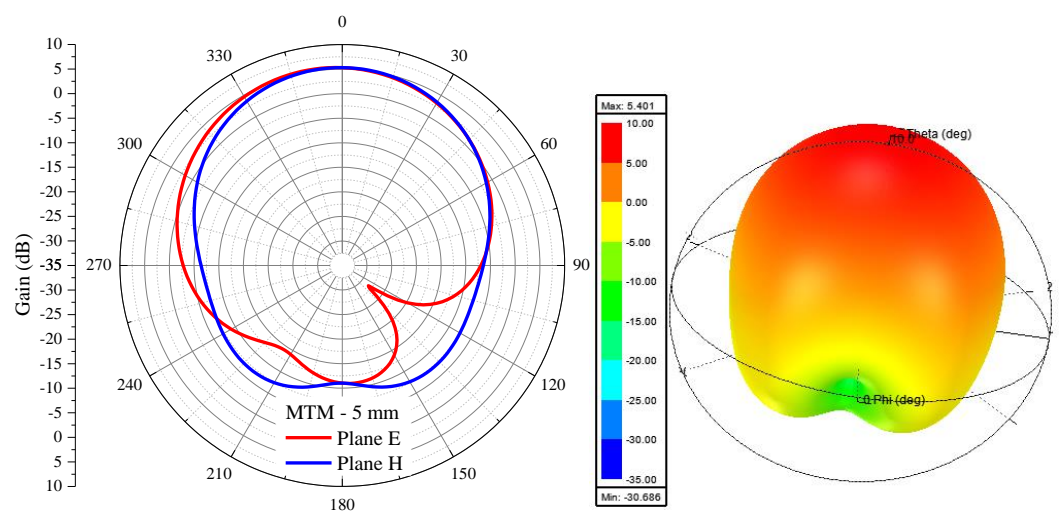

(c)

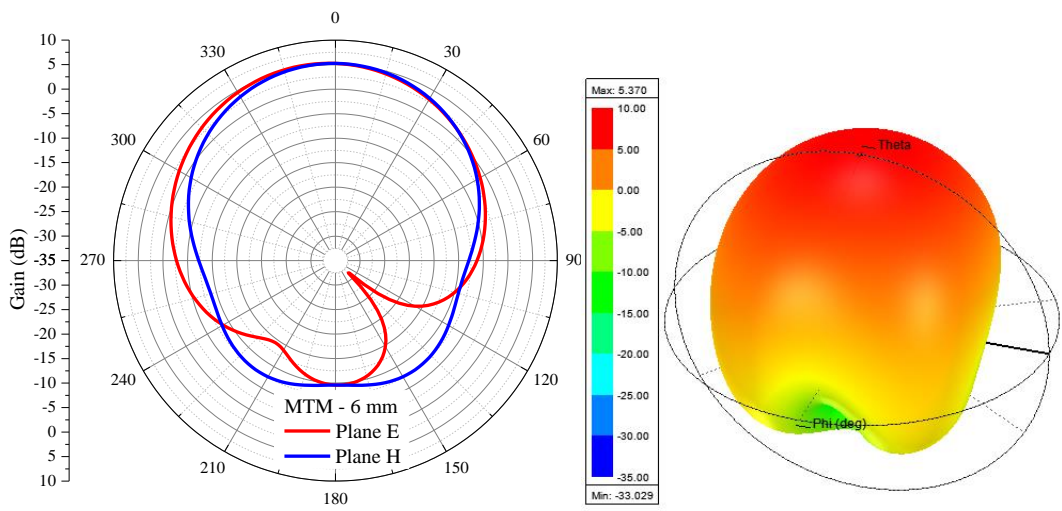

(d)

Fig. 13. 2D and 3D simulated diagram of MPAs gain (a) Without MTM (b) $\Lambda_{0}=4 \mathrm{~mm}$, (c) $\Lambda_{0}=5 \mathrm{~mm}$ (d) $\Lambda_{0}=6 \mathrm{~mm}$. 
Journal of Microwaves, Optoelectronics and Electromagnetic Applications, Vol. 19, No. 3, September 2020 DOI: http://dx.doi.org/10.1590/2179-10742020v19i3886

From the results obtained in this work, Table II presents a comparative summary of the parameters, for the simulated and measured results of MPAs with and without MTM.

TABLE II. COMPARISON OF SIMULATED AND MEASURED RESULTS FOR MPAS WITHOUT AND WITH MTM

\begin{tabular}{|c|c|c|c|c|c|c|}
\hline \multicolumn{3}{|c|}{ Parameters } & $\begin{array}{l}\text { Without } \\
\text { MTM }\end{array}$ & $\begin{array}{c}\text { MTM } \\
\Lambda 0=4 \mathrm{~mm}\end{array}$ & $\begin{array}{c}\text { MTM } \\
\Lambda o=5 \mathrm{~mm}\end{array}$ & $\begin{array}{c}\text { MTM } \\
\Lambda 0=6 \mathrm{~mm}\end{array}$ \\
\hline \multirow{2}{*}{$\begin{array}{l}\text { Frequency } \\
\quad(\mathrm{GHz})\end{array}$} & \multicolumn{2}{|l|}{ Simulated } & 5.80 & $5.30 ; 5.96$ & $5.60 ; 6.08$ & $5.79 ; 6.02$ \\
\hline & \multicolumn{2}{|l|}{ Measured } & 5.77 & $5.56 ; 5.75$ & 5.68 & 5.64 \\
\hline \multirow{2}{*}{$\mathrm{S}_{11}(\mathrm{~dB})$} & \multicolumn{2}{|l|}{ Simulated } & -20.40 & $-28.82 ;-34.07$ & $-23.26 ;-18.97$ & $-42.11 ;-13.16$ \\
\hline & \multicolumn{2}{|l|}{ Measured } & -28.33 & $-17.07 ;-26.50$ & -22.00 & -37.00 \\
\hline \multirow{2}{*}{$\begin{array}{c}\text { Bandwidth } \\
\text { (MHz) }\end{array}$} & \multicolumn{2}{|l|}{ Simulated } & 440 & $240 ; 370$ & 800 & 620 \\
\hline & \multicolumn{2}{|l|}{ Measured } & 380 & 460 & 490 & 390 \\
\hline \multirow{2}{*}{ Bandwidth (\%) } & \multicolumn{2}{|l|}{ Simulated } & 7.70 & $4.50 ; 6.20$ & 13.80 & 10.86 \\
\hline & \multicolumn{2}{|l|}{ Measured } & 6.10 & 8.17 & 8.54 & 6.93 \\
\hline \multirow{2}{*}{$\begin{array}{c}\text { Input } \\
\text { Impedance }(\Omega)\end{array}$} & \multicolumn{2}{|l|}{ Simulated } & $41.5+\mathrm{j} 1$ & $\begin{array}{c}53.5-\mathrm{j} 0.5 \\
49+\mathrm{j} 0.5 \\
\end{array}$ & $\begin{array}{c}56.5+\mathrm{j} 3.5 \\
61+\mathrm{j} 6 \\
\end{array}$ & $49.5-\mathrm{j} 2.5$ \\
\hline & \multicolumn{2}{|l|}{ Measured } & $56.12-\mathrm{j} 4.5$ & $\begin{array}{c}46.15-\mathrm{j} 0.02 \\
37.81+\mathrm{j} 1.68\end{array}$ & $42.36-\mathrm{j} 1.13$ & $49-\mathrm{j} 1$ \\
\hline VSWR (dB) & \multicolumn{2}{|l|}{ Simulated } & 1.65 & $1.08 ; 0.74$ & 1.20 & 0.30 \\
\hline \multirow{2}{*}{ Gain $(\mathrm{dB})$} & \multirow{2}{*}{ Simulated } & $\operatorname{Max}$ & 6.43 & 5.20 & 5.40 & 5.37 \\
\hline & & Min & -32.24 & -26.50 & -30.68 & -33.03 \\
\hline HPBW (dB) & Simulated & & 90.11 & 90.30 & 90.93 & 89.04 \\
\hline $\begin{array}{c}\text { Radiation } \\
\text { Efficiency (\%) }\end{array}$ & Simulated & & 80.45 & 53.64 & 67.5 & 67.27 \\
\hline
\end{tabular}

To validate the results obtained in this work, Table III shows a comparison between several works in the literature, in which it is possible to analyze the frequency at which the antenna operates, the type of resonator used in the making of the metamaterial, the bandwidth achieved and the gain of these antennas. 
Journal of Microwaves, Optoelectronics and Electromagnetic Applications, Vol. 19, No. 3, September 2020 DOI: http://dx.doi.org/10.1590/2179-10742020v19i3886

TABLE III. COMPARISON OF THE PROPOSED ANTENNA PARAMETERS WITH OTHERS IN THE LITERATURE

\begin{tabular}{|c|c|c|c|c|}
\hline $\begin{array}{l}\text { Reference } \\
\text { number }\end{array}$ & $\begin{array}{l}\text { Operating frequency } \\
\qquad(\mathbf{G H z})\end{array}$ & $\begin{array}{l}\text { Metamaterial } \\
\text { Resonator }\end{array}$ & $\begin{array}{c}\text { Bandwith } \\
(\%)\end{array}$ & $\begin{array}{l}\text { Gain } \\
\text { (dB) }\end{array}$ \\
\hline$[6]$ & 5.5 & $\begin{array}{c}\text { Circularly polarized MTM } \\
\text { based on ENG-TL }\end{array}$ & $10.86 \%$ & 4.17 \\
\hline [7] & 3.07 to 19.91 & $\begin{array}{l}\text { Two capacitance-loaded strips } \\
\text { (CLSs) }\end{array}$ & $146.56 \%$ & 5.62 to 8.57 \\
\hline [9] & $5.63 ; 5.76$ & Square SRR & $5.86 \% ; 4.16 \%$ & $4.4 ; 5.22$ \\
\hline$[10]$ & 5.8 & $\begin{array}{c}\text { Capacitively loaded loop } \\
\text { (CLL) }\end{array}$ & $65.5 \%$ & 10 \\
\hline [11] & 1.8. 2.4 & Hexagonal SRR & $81.63 \% ; 25.14 \%$ & --- \\
\hline [12] & $\begin{array}{l}2.28 ; 2.65 ; 4.8 \\
\quad 5.89 ; 8.73\end{array}$ & $\begin{array}{l}\text { Rectangular complementary } \\
\text { split ring resonator (RCSRR) }\end{array}$ & $\begin{array}{c}7.01 \% ; 5.66 \% \\
9.16 \% ; 5.43 \% \\
5.38 \%\end{array}$ & $\begin{array}{l}2.16 ; 1.91 ; 2.65 ; \\
\quad 2.81 ; 3.01\end{array}$ \\
\hline$[13]$ & 3.19 & SRR labyrinth & $600 \%$ & 3.18 \\
\hline$[15]$ & 1020 & Circular SRR & $4.12 \%$ & 5.75 \\
\hline [16] & $5.2 ; 5.8$ & Square SRR & $31.37 \%$ & 4.0 \\
\hline [19] & $10 ; 303$ & Square SRR & --- & $1.5 ; 1.1$ \\
\hline [22] & 3.08 to 14.10 & $\begin{array}{c}\text { Symmetric split ring resonator } \\
\text { (SSRR) }\end{array}$ & $128.28 \%$ & 4.54 to 6.12 \\
\hline [23] & 2.44 & Hybrid (SRR and CSRR) & $5.8 \%$ & 1.45 \\
\hline \multirow{3}{*}{ This work } & $5.3 ; 5.96$ & $\operatorname{CLL}\left(\Lambda_{o}=4 \mathrm{~mm}\right)$ & $8.17 \%$ & 5.2 \\
\hline & $5.6 ; 6.08$ & $\operatorname{CLL}\left(\Lambda_{0}=5 \mathrm{~mm}\right)$ & $8.54 \%$ & 5.4 \\
\hline & $5.79 ; 6.02$ & $\operatorname{CLL}(\Lambda o=6 \mathrm{~mm})$ & $6.93 \%$ & 5.37 \\
\hline
\end{tabular}

\section{CONCLUSION}

In this paper, an MTM geometry is characterized and inserted into the MPAs substrate with $9 \times 7$ element arrays. The main proposal is the construction and applicability of MTMs inserted in the substrate, with the possibility of manufacturing printed circuit boards that use the antenna structure. The distribution of the cells and their variations among them were chosen to verify the influence of the distance variation $\left(\Lambda_{0}\right)$ on the antenna performance. In this context, it was found that small variations in the $\pm \hat{y}$ direction of $\Lambda_{0}$ cause large variations in some antenna standardization parameters. Initially, the projected structures were analyzed through simulation using ANSYS HFSS ${ }^{\circledR}$ software version 19.2 and software Scilab, from which prototypes were fabricated, which allowed the experimental results to be obtained. The introduction of metamaterial in the MPA enabled a better performance, in the reflection coefficient $\left(S_{11}\right)$, bandwidth $(\mathrm{BW})$, impedance matching and electric field distribution, 
besides provoking the emergence of artificial modes that influenced the enlargement of the bandwidth. In adittion, it was verified that the proposed antenna has miniaturization capacity, according to the responses presented. However, there was a little decrease in a gain and radiation efficiency. The measured and simulated results were compared and showed good agreement.

\section{ACKNOWLEDGMENT}

The authors wish to acknowledge the UFRN/PPGEEC, IFPB/Campus João Pessoa for the structure support and UFERSA/PPGEE for the commercial software license ANSYS HFSS ${ }^{\circledR}$ software version 19.2 ( $\mathrm{n}^{\circ}$ 1058710). This study was financed in part by the Coordenação de Aperfeiçoamento de Pessoal de Nível Superior - Brasil (CAPES) - Finance Code 001.

\section{REFERENCES}

[1] D. A. Ketzaki and T. V. Yioultsis, "Metamaterial-based design of planar compact MIMO monopoles," IEEE Trans. on Antennas and Prop., vol. 61, pp. 2758-2766, 2013.

[2] V. G. Veselago, "The electrodynamics of substances with simultaneously negative values of E and mi," Soviet Physics Uspekhi, vol. 10, pp. 509-514, 1968.

[3] D. R. Smith, J. B. Pendry and M. C. K Wiltshire, "Metamaterial and negative refractive index," Scince, vol. 305, pp. 788792, 2004.

[4] D. C. Corrêa, U. C. Resende, F. S. Bicalho and Y. S. Gonçalves, "Design, optimization and experimental evalution of a F-shaped Multiband metamaterial antenna," Journal of Microw., Opt. and Electrom. Applic., vol. 17, pp. 590-603, 2018.

[5] M. T. Islam, Md. N. Rahman, Md. Samsuzzaman, M. F. Mansor and N. Misran, "Resonator-inspired metamaterial sensor: design and experimental validation for measuring thickness of multi-layered structures', Sensors, vol. 18, pp. 1-20, 2018.

[6] M. Ameen and R. K. Chaudhary, "Metamaterial-based circularly polarized antenna employing ENG-TL with enhanced bandwidth for WLAN applications," Electronics Letters, vol. 54, pp. 1152-1154, 2018.

[7] M. M. Islam, M. T. Islam, M. Samsuzzaman and M. R. I. Faruque, "Compact metamaterial antenna for UWB applications," Electronics Letters, vol. 51, pp. 1222-1224, 2015.

[8] C. Fang and F. Xu, "Miniaturized active metamaterial resonant antenna with improved radiation performance based on negative-resistance-enhanced CRLH transmission lines," IEEE Anten. and Wirel. Prop., vol. 17, pp. 1162-1165, 2018.

[9] J. L. da Silva, H. D. de Andrade, H. C. C. Fernandes, B. T. Isaac, I. S. Q. Júnior, J. P. P. Pereira and A. S. S. Neto "Microstrip patch antenna project with split ring resonator periodically arrayed on the substrate," Microw. Opl. Technol. Lett., vol. 57, pp. 2715-2720, 2015.

[10] A. H. Jabire, H. Zheng, A. Abdu and Z. Song, "Characteristic mode analysis and design of wide band MIMO antenna consisting of metamaterial unit cell," Electronics, vol. 8, pp. 68, 2019.

[11] T. Alam, M. R. I. Faruque and M. T. Islam, "Specific absorption rate reduction of multi-standard mobile antenna with double-negative metamaterial," Electronics Letters, vol. 51, pp. 970-971, 2015.

[12] T. Ali, A. W. S. Mohammad, R. C. Biradar, J. Anguera and A. Andújar, "A miniatirized metamaterial slot antenna for wireless applications," Int. Journal Electron. Commun., vol. 82, pp. 368-382, 2017.

[13] P. Dawar,N. S. Raghava and N.S., A. T. L. De, "UWB metamaterial-loaded antenna for C-band applications," Int. Journal of Ant. and Propag., vol. 82, pp. 368-382, 2017.

[14] P. Baccarelli, P. Burghignoli, G. Lovat and S. Paulotto, "Surface-wave suppression in a double-negative metamaterial grounded slab," IEEE Ant. and Wireless Prop. Letters, vol. 2, pp. 269-272, 2003.

[15] A. T. Devapriya and S. Robinson, "Investigation on metamaterial antenna for terahertz applications," Journal of Microw., Opt. and Electrom. Applic., vol. 18, pp. 377-389, 2019.

[16] S. Roy, K. L. Baishnab and U. Chakraborty, "Beam focusing compact wideband antenna loaded with mu-negative metamaterial for wireless LAN application', Progress In Electrom. Research, vol. 83, pp. 33-44, 2018.

[17] D. C. Ochoa, D. E. Senior, F. Lopes and E. R. Vera, "Performance analysis of a microstrip patch antenna loaded with array of metamaterial resonators," Intern. Symposium on Ant. and Propagation (APSURSI) 2016.

[18] P. K. Singh and G. Saini, "Log - Periodic terahertz antenna with square SRR metamaterial superstrate," Int. Journal of Engineering Research \& Technology, vol. 5, 2016.

[19] A. A. A. Abdelrehim and H. G. Shiraz, "High performance terahertz antennas based on split ring resonator and thin wire metamaterial structures," Microw. Opl. Technol. Lett., vol. 58, pp. 382-389, 2016.

[20] M. Koutsoupidou, N. Uzunoglu and I. S. Karanasiou, "Antennas on metamaterial substrates as emitting components for THz biomedical imaging," International Conference on Bioinformatics, 2012.

[21] Q. L. Zhang, L. M. Si, Y. Huang, X. Lv and W. Zhu, "Low-index-metamaterial for gain enhancement of planar terahertz antenna," AIP Advances, vol. 4, 2014. 
[22] S. S. Al-Bawri, H. H. goh, M. S. Islam, H. Y. Wong, M. F. Jamlos, A. Narbudowicz, M. Jusoh, T. Sabapathy, R. Khan and M. T. Islam, "Compact ultra-wideband monopole antenna loaded with metamaterial," Sensors, vol. $20,2020$.

[23] A. E. Hidalgo and F. M. Rizo, "Antena de microcinta con estructura híbrida metamaterial para 2.4 GHz," Revista chilena de ingeniería, vol. 27, pp. 22-23, 2019.

[24] F. Ma, Y. S. Lin, X Zhang and C. Lee. "Tunable multiband terahertz metamaterial using a reconfigurable electric splitring resonator array," Ligth: Science \& Applications, vol. 3, pp. e171, 2014.

[25] E. R. Vera, G. A. Osorio, M. A. Correa and D. E. Senior, "A submersible printed sensor based on a monopole-coupled split ring resonator for permittivity characterization," Sensors, vol. 19, 2019.

[26] E. Ahamed, M. R. I. Faruque, M. F. B. Mansor and M. T. Islam, "Polarization-dependent tunneled metamaterial structure with enhanced fields properties for X-band application,” Results in Physics, vol. 15, 2019.

[27] HFSSTM, "Getting Started with HFSS: Floquet Ports", Technical Report, 2016.

[28] R. W. Ziolkowski, "Design, fabrication, and testing of double negative metamaterials," IEEE Trans. on Antennas and Prop., vol. 51, pp. 1516-1529, 2003.

[29] A. B. Numan and M. S. Sharawi, "Extraction of material parameters for metamaterials using a full-wave simulator," IEEE Trans. on Antennas and Prop., vol. 55, pp. 202-211, 2013.

[30] M. M. Hosain, S. Kumari and A. K. Tiaway, "Compact filtenna for WLAN applications," Journal of Microw. and Electromagnetic Applications, vol. 18, pp. 70-79, 2019.

[31] C. A. Ballanis, “Antenna Theory: Analysis and Design,” New Jersey, 2005.

[32] D. K. Cheng, "Field and Wave electromagnetics," China, 1989.

[33] J. S. Hong and M. J. Lancaster, "Couplings of microstrip square open-loop resonators for cross-coupled planar microwave filters," IEEE Trans. on Microwave Theory and Techniques, vol. 44, pp. 2099-2109, 1996.

[34] L. Cong, Y. K. Srivastava and R. Singh, "Near-field inductive coupling induced polarization control in metasurfaces," Advanced Optical Materials, vol. 4, pp.848-852, 2016.

[35] Y. H. Chen, C. C. Chen, A. Ishikawa, M. H. Shiao, Y. S. Lin, C. N. Hsiao, H. P. Chiang and T. Tanaka, "Interplay of mutual electric and magnetic couplings between three-dimensional split-ring resonators," Optics Express, vol. $25,2017$.

[36] J. Powell, “Antenna design for ultra wideband radio,” Ph.D. Dissertation, MIT, Massachusetts, EUA, 2004. 